\title{
ПСИХОЛОГИЧЕСКИЕ ОСОБЕННОСТИ ЛИЧНОСТИ СТУДЕНТОВ, СКЛОННЫХ К УПОТРЕБЛЕНИЮ АЛКОГОЛЯ
}

\section{PSYCHOLOGICAL CHARACTERISTICS OF ALCOHOL-PRONE STUDENTS}

\section{Ivanov \\ D. Khachunts}

Summary: The article contains an analysis of current perceptions of the psychological characteristics of persons who are inclined to drink alcohol. Current global statistics on the identification of different chemical and non-chemical addictions are presented. The risks of different types of addictions arising from the epidemiological situation in the world and Russia are considered. The authors present the progress of experimental work on the study of psychological characteristics of students inclined and not inclined to drink alcohol. The results of the study of alcohol addiction in students are presented. Personal characteristics of students with a propensity for alcohol addiction are identified.

Keywords: student, alcohol addict, addictive behavior, personality, epidemiological situation, coronavirus.

\author{
Иванов Дмитрий Викторович \\ К.nсх.н., дочент, Самарский государственный \\ сочиально-педагогический университет \\ avatary@yandex.ru \\ Хачуни Давид Юрьевич \\ Самарский государственный социально-педагогический \\ университет \\ hachuns94@gmail.com
}

Аннотация: В статье дан анализ современных представлений о психологических особенностях лиц, склонных к употреблению алкоголя. Представлена современная мировая статистика выявления различных химических и нехимических зависимостей. Рассмотрены риски возникновения различных видов зависимостей как следствие эпидемиологической ситуации в мире и России. Авторы излагают ход экспериментальной работы по исследованию психологических особенностей личности студентов, склонных и не склонных к употреблению алкоголя. Представлены результаты изучения склонности к алкогольной зависимости у студентов. Выявлены личностные особенности студентов, имеющих склонность к алкогольной зависимости. Представлена характеристика личности студентов, имеющих склонность к алкогольной зависимости.

Ключевые слова: студент, алкогольная зависимость, аддиктивное поведение, личность, эпидемиологическая ситуация, коронавирус.

2016 года количество детей-алкоголиков в Казахстане увеличилось за три года в 10 раз, пьющих подростков стало больше в 2 раза [7, с. 49]. М.С. Калиев обращает внимание на то, что «2-3 года тому назад в Казахстан пришли спайсы. 2-3 употребления в курительных смесях этой «химии» вызывает зависимость с явным абстинентным синдромом» [8]. Л.И. Окунева, Д.С. Дарбаев отмечают, что «с ростом компьютеризации во всех странах, и в Казахстане в том числе, будет увеличиваться и количество людей с интернет-аддикцией, особенно среди учащейся молодёжи» [9, с. 115].

Говоря о химических зависимостях, С.А. Кулаков, дает определение аддиктивному поведению - «это одна из форм деструктивного поведения, которая характеризуется стремлением к бегству от действительности с помощью изменения своего психического состояния с помощью приема каких-либо веществ» [10, с. 111]. Как указывает О.В. Липунова, «уход от реальности в виде своеобразного «бегства» часто заключается в сосредоточении подростка на узконаправленной сфере деятельности (часто негармоничной и разрушающей личность), игнорирующей все остальные сферы деятельности» [11, с. 10]. Более широкое определение встречаем в работах В.Д. Менделевича: «аддиктивное поведение - это один из типов девиантного (отклоняющегося) поведения с формированием стремления человека к уходу от ре- 
альности путем искусственного изменения своего психического состояния посредством приема некоторых веществ или постоянной фиксацией внимания на определенных видах деятельности с целью развития и поддержания интенсивных эмоций» $[12$, с. 34].

Сегодня эпидемиологическая ситуация в мире и в России, обусловленная распространением коронавируса, и вызванные этой ситуацией 2-3 месяца, проведенные в самоизоляции, актуализировали такие формы девиантного поведения, как интернет-зависимость, пищевая зависимость и употребление алкоголя. В течение вынужденной самоизоляции, большая часть активности населения и молодежи была связана с действиями, осуществляемыми посредством сети Интернет. Покупки, учеба, общение, трудовая деятельность и многие другие виды поведения осуществлялись посредством сети Интернет.

Формирование пищевой зависимости и последующее ожирение может стать результатом гиподинамии в условиях самоизоляции. Более опасный вариант развития пищевой зависимости - привыкание к употреблению блюд из ресторанов категории фаст-фуд. Такой вариант формирования зависимости вероятен, так как в последние 2-3 месяца наблюдается повышенный спрос на заказ блюд именно в таких ресторанах. Так, например, агентство «РИА-новости» пишет: «Введение режима самоизоляции на фоне коронавируса сильно изменили потребительские привычки москвичей - они стали чаще заказывать еду с доставкой на дом и тратят на нее больше, чем прежде» [13]. Издание «Правда.Ру» отмечает: «... раньше большинство пользователей DeliveryClub лакомились вредной пищей в основном по выходным, то сейчас, по заявлениям компании, значительно выросло количество заказов в будни» [14]. Пищевая зависимость исследуется такими авторами как C.F. Moore, V. Sabino, G.F. Koob, P. Cottone, E. Schulte, M. Potenza, A. Gearhardt и др. [15]. Мы считаем, что негативные последствия самоизоляции в виде увеличения количества молодых людей с пищевой зависимостью и интернет-зависимых мы увидим в ближайшие месяцы и годы. Формирование зависимости - это длительный процесс, зависимость не формируется одномоментно. Негативные последствия проявятся не сразу, по прошествии месяцев, и ещё потребуют своего изучения.

Однако уже сейчас мы можем видеть отчеты торговых сетей о возросших продажах алкоголя. Издание «Ведомости» пишет: «компания Nielsen зафиксировала всплеск продаж алкоголя в крупнейших торговых сетях в последнюю неделю марта». Далее: «...продажи водки за 23-29 марта в натуральном выражении увеличились на 31\% по сравнению с аналогичной неделей 2019 г., а в сравнении со среднегодовым значением темп роста ускорился втрое. Похожая ситуация и с пивом: его продажи за этот период выросли на 25\%, темп прироста также утроился. Продажи виски выросли на 47\%, прирост ускорился в 2,5 раза» [16].

Издание «Газета.ru»: «продажи в категории алкогольной продукции (без учета тихих вин) уверенно росли весь прошлый месяц. Если в первую неделю марта прирост составил 2,6\%, то во вторую уже $11,9 \%$, а в третью и четвертую недели месяца - 23,8\% и 25,4\% соответственно. При этом ускорение темпов роста алкогольной индустрии поддерживается увеличением продаж пива: на него пришлось 77,6\% продаж за последние две недели марта. Также в прошлом месяце активно росли продажи биттеров: с 16 по 22 марта прирост составил 121\%, а с 22 по 29 - 113\% к аналогичному периоду прошлого года» [17].

Издание «Lenta.ru»: «...продажи виноторговой компании Alianta Group в марте увеличились в среднем на 20 процентов по сравнению с мартом прошлого года. Группа компаний Simple за этот месяц увеличила свои продажи на 10-20 процентов через винотеки SimpleWine. У компании «Ладога дистрибьюшен» продажи за последние семь дней выросли на 20-30 процентов по сравнению с первой неделей марта» [18].

Анализу алкогольной зависимости посвящены работы таких авторов как Chung, T., Creswell, K.G., Bachrach, R., Clark, D.B., \& Martin, C.S., Brown, S.A., Brumback, T., Tomlinson, K., Cummins, K., Chen, C. M., Yi, H.Y., Faden, V.B. и др. [19]. Проблема алкоголизма становится сегодня поистине глобальной и может затронуть каждую семью. Алкогольное распространение связано с искусственно выработанными ценностями общества. Считается, что одними из основных потребителей алкогольной продукции сегодня являются студенты. Достаточно большое распространение проблема употребления алкоголя получила в среде студентов, приехавших на учебу из окраин в крупные города. Такие студенты находятся вдали от родителей, без их присмотра.

Целью нашего исследования было выявление личностных особенностей студентов, склонных к употреблению алкоголя. По нашему мнению, студенты, склонные к употреблению алкоголя, обладают рядом личностных особенностей: низкий уровень самоконтроля и повышенная тревожность. Исследование проводилось на базе Самарского государственного социально-педагогического университета (СГСПУ) г.о. Самара среди студентов 2-4 курсов факультета психологии и специального образования студентов в возрасте от 19-25 лет. В исследовании приняли участие 50 студентов.

В ходе исследования у студентов определялись уровни алкоголизации личности, вероятность наличия алкоголизма, личностные особенности. Рассмотрим методики исследования. Для выявления ранних признаков алкоголизма (склонности к алкогольной зависимости) использовался опросник, разработанный К.К. Яхиным и В.Д. Менделевичем [20]. Для диагностики вероятности 
наличия алкоголизма использовалась методика «Тест на алкоголизм Университета штата Мичиган (The Michigan alcohol screening test, MAST)» [21]. Методика содержит 24 вопроса. Для выявления личностных особенностей студентов использовался 16-факторный личностный опросник (Автор Р. Кеттелл) [22]. 16-факторный опросник Р. Кеттелла позволяет выяснить особенности характера, склонностей и интересов личности. Сравнение значимых для исследования показателей двух экспериментальных групп («не зависимые от алкоголя» и «зависимые от алкоголя») производилось с помощью математической статистики с применением U-критерия Манна Уитни.

Результаты диагностики склонности к алкогольной зависимости по «Опроснику для выявления ранних признаков алкоголизма» (К.К. Яхин, В.Д. Менделевич) показали, что 74\% испытуемых имеют низкий уровень склонности к алкогольной зависимости, «уровень здоровья». Для таких студентов алкоголь не является важной жизненной ценностью. Учащиеся могут отдыхать и проводить время отдыха без употребления алкогольных напитков. У $26 \%$ учащихся выявлена склонность к алкогольной зависимости («уровень бытового пьянства» и «уровень алкоголизма»). Такие студенты уже не видят свой отдых без алкоголя, получают удовольствие от алкогольных напитков, им нравится действие, которое оказывает алкоголь на организм. Такие студенты находятся в зоне высокого риска. Им не интересен здоровый образ жизни, так как у них уже существует потребность в алкоголе. Такие учащиеся не осознают его пагубного воздействия на организм.

Для диагностики вероятности наличия алкоголизма использовалась методика «Тест на алкоголизм Университета штата Мичиган (MAST)». Результаты диагностики по всей выборке студентов показали, что 68\% опрашиваемых набрали баллы в диапазоне от 0 до 4, что свидетельствует об отсутствии признаков алкоголизма. Такие студенты считают, что могут без труда остановиться, даже после того как употребили 1-2 рюмки спиртного. Они могут прекратить употребление алкоголя тогда, когда захотят. Также они трепетно относятся к своему здоровью и считают, что алкоголь в больших количествах вредит их организму и психике.

Однако 24\% студентов исследуемой выборки набрали от 4 до 7, что позволяет отнести их к уровню «подозрение на алкоголизм». У таких студентов зачастую принято хранить дома алкоголь. Часто они не в силах прекратить потребление алкоголя после того, как приняли 1-2 рюмки спиртного. Как правило, такие студенты употребляют больше других на мероприятиях и праздниках.

Наибольшую вероятность развития алкоголизма имеет небольшой процент респондентов - 8\% студентов, которые набрали свыше 7 баллов - уровень «вероятно наличие алкоголизма». Нахождение человека на уровне «вероятно наличие алкоголизма» не позволяет ему прекратить употребление при возникновении такого желания. В учебной деятельности таких студентов отмечается неуспеваемость, одной из косвенных причин которой является недосыпание, а также заторможенность. Они зачастую испытывают чувство вины из-за своего пьянства. Бывало такое, что, проснувшись утром, не могут вспомнить события вчерашнего вечера. Такие студенты имеют слабый самоконтроль по отношению к алкоголю. Они переживают из-за своих пристрастий к спиртному, но не стремятся искоренить эти пристрастия.

Проведенная диагностика с использованием опросника К.К. Яхина и В.Д. Менделевича и методики «Тест на алкоголизм Университета штата Мичиган (MAST)» позволила нам разделить нашу выборку на две подгруппы (две экспериментальные группы): «зависимые» и «независимые» от алкоголя. К экспериментальной группе № 1 мы отнесли 34 студента, которые по результатам диагностики «Теста на алкоголизм Университета штата Мичиган» набрали менее 4 баллов, и при этом по результатам методики К.К. Яхина и В.Д. Менделевича имеют низкий уровень склонности к алкогольной зависимости («уровень здоровья»). К экспериментальной группе № 2 мы отнесли 16 студентов, которые по результатам «Теста на алкоголизм Университета штата Мичиган» набрали свыше 4 баллов, либо которые по методике К.К. Яхина и В.Д. Менделевича обнаружили склонность к алкогольной зависимости («уровень бытового пьянства» и «уровень алкоголизма»).

Для выявления личностных особенностей студентов использовался 16-факторный личностный опросник (Автор Р. Кеттелл). Результаты диагностики экспериментальной группы №1 («независимые» от алкоголя) показали по фактору A «замкнутость-общительность» (ср. балл 17), что студенты данной группы склонны к добродушию, легки в общении, легко выражают свои эмоции; проявляют внимание к людям, готовы сотрудничать. Такие студенты предпочитают деятельность, предполагающую контакты с людьми, позитивно относятся к критике.

Средний балл по фактору В «интеллект» (ср. балл 5) показал, что студенты этой группы склоны медленнее понимать материал при обучении, предпочитая конкретную, буквальную интерпретацию.

Результаты по фактору С «эмоциональная нестабильность - эмоциональная стабильность» (ср. балл 21) позволяют охарактеризовать студентов, не склонных к употреблению алкоголя, как эмоционально зрелых, устойчивых, невозмутимых. Им свойственна высокая способность к соблюдению общественных моральных норм.

Средний балл по фактору $\mathrm{E}$ «подчиненность - доминантность» (ср. балл 17) характеризует исследуемых студентов как самоутверждающихся, независимых, агрес- 
сивных, упрямых (доминантных).

Результаты диагностики экспериментальной группы №1 («независимые» от алкоголя) по фактору F «сдержанность - экспрессивность» (ср. балл 20) показали, что студентов данной группы можно охарактеризовать как веселых, активных, разговорчивых, беззаботных, отчасти импульсивных.

Далее перечислим личностные особенности студентов, не склонных к употреблению алкоголя, выявленные по другим факторам:

- сознательность, настойчивость, обязательность студента (по фактору G «низкая нормативность поведения - высокая нормативность поведения» - ср. балл 15),

- общительность, смелость, спонтанность. Может небрежно относиться к деталям, не реагировать на сигналы об опасности (по фактору $\mathrm{H}$ «робость - смелость» - ср. балл 24),

- независимость, склонность полагаться на себя, реалистичность (по фактору I «жесткость - чувствительность» - ср. балл 17),

- приспособляемые, веселые не стремятся к конкуренции, проявляют заботу о других, хорошо работают в группе (по фактору L «доверчивость - подозрительность»-ср. балл 6),

- имеют развитое воображение, погружены во внутренние потребности, заботятся о практических вопросах (по фактору $\mathrm{M}$ «практичность - мечтательность»- ср. балл 15),

- склонны к отсутствию утонченности, к сентиментальности и простоте, иногда грубоваты и резки, обычно естественны и спонтанны (по фактору $\mathrm{N}$ «прямолинейность - дипломатичность» ср. балл 8),

- безмятежны и невозмутимы, их трудно вывести из себя, уверенные в себе и своих способностях (по фактору О «спокойствие - тревожность» ср. балл 5),

- поглощены интеллектуальными проблемами, скептичны и стараются вникнуть в сущность идей, терпимы к несообразностям и к изменениям (по фактору Q1 «консерватизм - радикализм» - ср. балл 14),

- любят общение, предпочитают работать и принимать решения совместно с другими людьми, нуждаются в поддержке со стороны группы (по фактору Q2 «конформизм - нонконформизм» ср. балл 3),

- контролируют эмоции и поведение, заботятся о социальной репутации, иногда склонны к упрямству (по фактору Q3 «низкий самоконтроль - высокий самоконтроль» - ср. балл 18),

- склонны к расслабленности, уравновешенности, удовлетворенности (по фактору Q4 «расслабленность - напряженность» - ср. балл 2).
Таким образом, в результате исследования личностных особенностей студентов экспериментальной группы №1 («независимые» от алкоголя) было установлено, что эти студенты склонны к добродушию, легкости в общении, готовы к сотрудничеству, внимательны к людям, мягкосердечны, эмоционально зрелые, устойчивые. Соблюдают общественные моральные нормы. Студенты данной группы безмятежны, их трудно вывести из себя, уверенные в себе и своих способностях, склонны к расслабленности, уравновешенности, удовлетворенности, контролируют эмоции и поведение, заботятся о социальной репутации, иногда склонны к упрямству.

Результаты исследования личностные особенностей студентов экспериментальной группы № 2, имеющих склонность к алкогольной зависимости, показали схожесть по большинству факторов с группой студентов, не склонных к употреблению алкоголя. Различия по большинству факторов оказались не значимы. Однако по четырем факторам личностного опросника Р. Кеттелла с использованием U-критерия Манна Уитни все же были обнаружены статистически значимые различия между экспериментальными группами. Различия обнаружены по факторам O «спокойствие-тревожность», Q2 «конформизм-нонконформизм», Q3 «низкий самоконтроль - высокий самоконтроль», Q4 «расслабленность - напряженность».

Студенты экспериментальной группы № 2, имеющие склонность к алкогольной зависимости, обладают такими личностными особенностями:

- неустойчивость, напряженность в трудных жизненных ситуациях, легко теряют присутствие духа, часто застенчивы, им трудно вступить в контакт с другими людьми (по фактору О «спокойствие тревожность» - ср. балл 8),

- студенты часто разобщены с группой, являются индивидуалистами, склонны идти собственной дорогой, принимать собственные решения, действовать самостоятельно, часто не считаются с общественным мнением (по фактору Q2 «конформизм - нонконформизм» - ср. балл 8),

- студенты, склонные к алкогольной зависимости, имеют слабую волю и плохой самоконтроль, их деятельность характеризуется неупорядоченностью и импульсивностью, зависимы от настроения, обладают низкой дисциплинированностью, (по фактору Q3 «низкий самоконтроль - высокий самоконтроль»-ср. балл 4),

- испытывают возбужденность, которая требует определенной разрядки. Такое состояние может превратиться в психосоматическое нарушение: снижается эмоциональная устойчивость, нарушается равновесие, может проявляться агрессивность. Часто испытывают беспокойство, раздражительность (по фактору Q4 «расслабленность - напряженность» - ср. балл 9). 
Подводя итоги проведенному исследованию, отметим, что по большей части личностных особенностей, студенты, имеющие склонность к алкогольной зависимости, и свободные от нее, не различаются. При этом всё же существуют значимые различия в личностных особенностях студентов, имеющих и не имеющих склонность к алкогольной зависимости. В частности, у студентов, склонных к алкогольной зависимости, обнаружены нонконформизм, неустойчивость, напряженность в трудных жизненных ситуациях, они легко теряют присутствие духа, часто застенчивы, им трудно вступить в кон- такт с другими людьми. Они часто разобщены с группой, являются индивидуалистами, склонны идти собственной дорогой, принимать собственные решения, действовать самостоятельно, часто не считаются с общественным мнением, имеют слабую волю и низкий самоконтроль, деятельность характеризуется неупорядоченностью и импульсивностью, зависимы от настроения. Студенты, имеющие склонность к алкогольной зависимости, испытывают беспокойство, раздражительность и возбужденность, которые требует определенной разрядки.

\section{ЛИТЕРАТУРА}

1. Чухрова М.Г. Современные представления о поведенческих аддикциях // Сибирский педагогический журнал. 2014. № 5. С. 105-110.

2. Sahebihagh M.H., Fakhari A., Hajizadeh M. Internet Addiction and Interpersonal Communication Skills Among High School Students in Tabriz, Iran. Iranian Journal of Psychiatry and Behavioral Sciences. 2017 June; 11(2):e4778. doi: 10.5812/ijpbs.4778.

3. Rahardjo, Wahyu. Harga Diri dan Adiksi Internet: Tinjauan Meta-Analisis. Buletin Psikologi, [S.I.], v. 27, n. 1, p. 70-86, june 2019. doi.org/10.22146/ buletinpsikologi.40306.

4. Антилогова Л.Н., Лазаренко Д.В. Психологические особенности аддиктивного поведения студентов // Психопедагогика в правоохранительных органах. 2014. № 2 (57). C. 40-43.

5. Семенова 0.Ю. Психофизиологические и психологические особенности подростков с риском разных видов аддикций: автореф. дис. .... канд. психол. наук. СПб. 2012. -23 C.

6. Нашкенова А., Жамалиева Д., Жолаушибекова А. Распространённость алкоголизма в Казахстане // Вестник Казахского Национального медицинского университета. 2015. № 2. С. 201-205.

7. Морозова Т.А. Особенности медико-социальной работы с лицами, употребляющими алкоголь и наркотики, в Казахстане // Медико-социальные и психологические аспекты безопасности промышленных агломераций: материалы Международной научно-практической конференции. - Екатеринбург: УрФу, 2016. С. 48-55.

8. Калиев М.С. Употребление психоактивных веществ (ПАВ) [Электронный ресурс]. - URL: http://densaulyk.gov.kz/language/ru/2019/05/upotrebleniepsihoaktivnh-veshtestv-pav/ (дата обращения: 11.07.2019).

9. Окунева Л.И., Дарбаев Д.С. Компьютерная зависимость как базовая аддикция современного общества // Вестник Северо-Казахстанского государственного университета имени Манаша Козыбаева. №4(29). 2015. С. 111-115.

10. Кулаков С.А. Психотерапия и психопрофилактика аддиктивного поведения у подростков. - СПб.: Гардарика, 2003. -470 с.

11. Липунова 0.В. Психология отклоняющегося поведения: учебное пособие. - Москва: ФЛИНТА, 2016. - 377 с.

12. Менделевич В.Д. Руководство по аддиктологии. - СПб.: Речь, 2007. - 768 с.

13. Исследование: москвичи стали больше тратить на еду в самоизоляции [Электронный ресурс]. - URL: https://ria.ru/20200406/1569613134.html (дата 06ращения: 17.07.2020)

14. Россияне во время самоизоляции стали есть больше сладостей и фастфуда [Электронный ресурс]. - URL: https://www.pravda.ru/news/society/1493137sladosti (дата обращения: 17.07.2020)

15. Schulte, E., Potenza, M. \& Gearhardt, A. How much does the Addiction-Like Eating Behavior Scale add to the debate regarding food versus eating addictions? // International Journal of Obesity volume 42, 946(2018). https://doi.org/10.1038/ijo.2017.265.

16. Россияне самоизолировались с алкоголем [Электронный ресурс]. - URL: https://www.vedomosti.ru/business/articles/2020/04/08/827537-rossiyanealkogolem (дата обращения: 17.07.2020)

17. В поисках истины: россияне закупаются вином [Электронный ресурс]. - URL: https://www.gazeta.ru/business/2020/04/08/13041025.shtml (дата 06ращения: 17.07 .2020$)$

18. Россияне начали массово скупать алкоголь [Электронный ресурс]. - URL: https://lenta.ru/news/2020/03/29/alco/ (дата 0бращения: 17.07.2020)

19. Chung, T., Creswell, K. G., Bachrach, R., Clark, D. B., \& Martin, C. S. (2018). Adolescent binge drinking: Developmental context and opportunities for prevention. Alcohol Research: Current Reviews, 39(1), 5-15.

20. Менделевич В.Д. Психология девиантного поведения: учебн. пособ. - М.: МЕДпресс, 2001. - 432 с.

21. Teitelbaum L, Mullen B. (2000) Validity of the MAST in psychiatric settings: A META-analytic integration. Michigan Alcoholism Screening Test. Journal of Studies on Alcohol, 61(2):254-261.

22. Практикум по психодиагностике / авт.-сост. А.И. Гарбер, Д.В. Иванов, С.К. Бердибаева. - Алматы: Казак университеті, 2019. - 365 с.

(с) Иванов Дмитрий Викторович (avatary@yandex.ru), Хачунц Давид Юрьевич (hachuns94@gmail.com).

Журнал «Современная наука: актуальные проблемы теории и практики» 